\title{
Dalgacık Dönüşümlü Yapay Sinir Ağlarıyla Günlük Akım Serilerinin Tahmini
}

\author{
Erol YABAR, Mehmet Cihan AYDIN* \\ Bitlis Eren Üniversitesi, Inşaat Mühendisliği Bölümü, Bitlis \\ (ORCID: 0000-0002-1158-4270) (ORCID: 0000-0002-5477-1033)
}

\begin{abstract}
$\ddot{O} \mathbf{z}$
Yapay Sinir Ağları (YSA) insan beyninin geçmiş tecrübelerinden ve eğitiminden yola çıkarak karmaşı problemleri kapalı kutu şeklinde çözmeye yarayan gelişmiş bir yöntemdir. Çok fazla değişken içeren hidrolojik süreçlerin parametrik modelleri yerine YSA gibi kapalı kutu modellerin kullanımı daha kullanışlı olabilmektedir. Özellikle, akarsulardaki günlük veya aylık akım serileri su yapılarının güvenli şekilde tasarımı için önem arz eder. Bu çalışmada Bitlis Deresi'ne ait 2008-2011 yılları arası günlük akım serileri YSA yardımıyla modellenmiştir. Bu amaçla, standart ve dalgacık dönüşümlü olmak üzere iki farklı YSA modeli kullanılmıştır. Standart YSA modeli istatistiksel olarak iyi sonuç vermekle birlikte yıl içindeki ekstrem pik debileri tahmin etmekte yetersiz kalmıştır. Dalgacık dönüşümlü YSA model ise ekstrem pik debilerle birlikte daha yüksek doğrulukta sonuç vermektedir. Elde edilen sonuçlara balı olarak akarsulardaki akım serilerinin tahmininde dalgacık dönüşümlü YSA modellerin oldukça başarılı olduğu ve bu gibi hidrolojik süreçlerin modellemesinde kullanılabileceği sonucuna varılmıştır.
\end{abstract}

Anahtar kelimeler: Yapay sinir ağları, dalgacık dönüşümü, akım serileri, Bitlis Deresi

\section{Estimation of Daily Flow Series by Wavelet Transformed Artificial Neural Networks}

\begin{abstract}
Artificial Neural Network (ANN) is an advanced method which can be used to solve complicated problems as a black-box model based on experience and training of human brain. The use of black-box models such as ANN can be more useful than the multi-parameters model for hydrological process. Especially, the daily and monthly flow series of the streams is most important to design and operate the water structures safely. In this study, the daily flow series between 2008 and 2011 were modelled using ANN models. For this purpose, two different ANN models that are standard and wavelet transformed ANN models were used. Although the standard ANN model gave good results statistically with high correlation, it is insufficient to estimate the extreme peak flow values in the year. Wavelet-ANN (WANN) model yielded more accurate results with the extreme peak flow values. Depending on the findings, it is concluded that the WANN models is quite successful to estimate the flow series of the stream and it can be easily used in modelling such hydrological process.
\end{abstract}

Keywords: Artificial neural network, wavelet transform, flow series, Bitlis Stream.

\section{Giriş}

Ülkemizde ve dünyada artan nüfusa ve buna bağlı suya ihtiyaçların artmasından dolayı suyun ve su kaynakların etkili bir şekilde kontrolünün sağlanması, su kaynakların akım özellikleri hem nitel hem nicel özelliklerin belirlenmesi önem arz etmektedir. Fakat doğal olaylar, iklimin değişmesi gibi nedenler su kaynaklarının debi akışını değiştirmekte ve bunun kontrolünün sağlanmasını zorlaştırmaktadır. Mühendislik çalışmalarıyla suyun kontrolünün sağlanması için öncelikle zaman içinde gelebilecek suyun tahminini yapmak gerekir. Fakat hidrolojik olaylar çok sayıda rastgele değişken içerdiğinden bu süreçlerin tahminleri oldukça güçtür. Bu tür çalışmalarda sıkça istatistik yöntemlerden

*Sorumlu yazar: mcaydin@gmail.com

Geliş Tarihi: 22.08.2019, Kabul Tarihi: 20.03.2020 
faydalanılmaktadır. Son yıllarda gelişme eğilimi göstermekte olan Yapay Sinir Ağları (YSA) özellikle hidrolojik süreçler gibi çok fazla rastgele değişken içeren verilerin kapalı kutu analizinde başarılı olduğu görülmektedir. Yapay Sinir Ağları insan beyninin çalışma prensibinden esinlenerek geliştirilen bilgisayar programlarıdır [1]. YSA bilgisayar programına öğretmeyi sağlayarak olaylar hakkında tahmin modeli oluşturmak için kullanılan yöntemdir.

Literatürde Yapay Sinir Ağları (YSA) kullanılarak pek çok nehirde benzer çalışmalar yapılmıştır. Bunlardan bazıları şu şekilde sıralanabilir: Kızılaslan vd. [2] Aşağı Sakarya Nehri akımlarını yapay sinir ağları kullanarak yüksek bir doğrulukla tahmin etmişlerdir. Okkan ve Mollamahmutoğlu [3] Yiğitler Çayı günlük akımlarını, regresyon modeli ve YSA ile modellemiş, YSA ile kurulan modelin regresyon modeline göre daha başarılı olduğunu belirtmişlerdir. Gemici vd. [4] akarsulardaki debi değişimlerinin YSA modelleri üzerinde çalışmış ve bu tür hidrolik süreçlerde oldukça etkili olduğunu göstermişlerdir. Hsu vd. [5] ABD'deki Missisippi akarsu havzası üzerindeki günlük yağış-akış modellemesi için farklı modelleri (Kavramsal, klasik ve YSA gibi) içeren kapsamlı bir çalışma yürütmüştür. Bu çalışma sonucunda YSA tekniğinin diğer kavramsal ve klasik yöntemlerden çok daha iyi sonuç verdiği belirtilmiştir. Nourani vd. [6] çalışmalarında, ikinci bir yöntem olarak dalgacık dönüşümlü ANFIS modelini kullanarak iki ana değişkenli zman serilerini dalgacık dönüşümü kullanarak bazı çok frekanslı zman serilerine ayrıştırmıştır. Nourani vd. [6] dalgacık dönüşümleriyle verilerin ön işleminin yapay sinir ağları modellerinin tahmin yeteneğini arttırdığını belirtmişlerdir. Yüksek tahmin ve iyileştirme yeteneklerinden dolayı son yıllarda birçok araştırmacı hidrolojik zaman serilerinin tahmin ve modellemesinde dalgacık dönüşümlü yapay sinir ağları $(W A N N)$ modellerini kullanmaya başlamıştır [7-11]. Nourani vd. [12] yağış-akış ilişkisinin modellenmesi için iki farklı hibrid yapay zekâ modeli önermişlerdir. Alizadeh vd. [10] Told akarsu havzasının gelecekteki yağış ve akış tahminleri için dalgacık dönüşüm ve yapay sinir ağlarının birleşimi (WANN) yeni bir yöntem önermiştir. Çalışma sonucu önerilen yöntemin klasik yöntemlere göre daha iyi sonuç verdiğini göstermiştir. Dalgacık dönüşümü, 1980'lerin başından bu yana artan bir popülerlikle kullanılmaktadır. Ancak Fourier dönüşümünün yaygın olarak kullanılmasının bazı sakıncaları doğmuştur. Frekans alanına dönüşümde zaman bilgisi kaybolduğu belirtilmektedir. Bir sinyalin Fourier dönüşümüne bakarken, belirli bir olayın ne zaman gerçekleştiğini söylemek imkânsızdır ancak dalgacık analizi, daha kesin düşük frekanslı bilgi almak istediğimiz uzun zaman aralıklarının ve yüksek frekans bilgisi istediğimiz daha kısa aralıkların kullanılmasına olanak sağlar [6]. Dalgacık dönüşümleri, ana zaman serilerinin faydalı ayrıştırmalarını sağlar, böylece dalgacık dönüşümlü veriler, çeşitli çözünürlük seviyelerinde yararlı bilgiler yakalayarak tahmin modelinin kabiliyetini geliştirir. Bu nedenle, giriş verisi olarak çok ölçekli sinyaller kullanan bir hibrid ANN-dalgacık modeli, tek bir model girişi yerine daha muhtemel tahminler sunabilir [13].

Debi ölçümü zor ve masraflı bir işlem olduğundan, geçmiş akım verilerinden yararlanarak gelecekteki akım değerlerin tahminin yapılması su kaynakların kullanımı ve kontrolü açısından önemli bir konudur. Su yapılarının tasarımı açısından en önemli hidrolojik veri, akarsuların uzun yıllar boyu getirdikleri debi miktarlarıdır. Akarsu debileri belirlenmesinde ölçümlerin yanında birçok ampirik bağıntı da geliştirilmiştir. Fakat geleceğe dönük akış tahminleri, eksik verilerinin tamamlanması gibi işlemlerde zaman serilerinin analizi önemlidir. Son yıllarda yapılan çalışmalar göstermiştir ki; YSA gibi sezgisel yöntemler çok fazla değişken ve belirsizlik içeren hidrolojik süreçlerin modellemesinde oldukça etkilidir. Bu yöntemlerle dalgacık dönüşümü gibi tekniklerin birlikte uygulanması periyodik yapılı süreçlerin daha başarılı bir şekilde modellemesine katkıda bulunabilmektedir. Bu çalışmada Bitlis Çayı akım verilerinin dalgacık dönüşümlü yapay sinir ağlarıyla modellemesine çalışılmıştır. Öncelikle Bitlis Çayı üzerinde DSİ akım gözlem istasyonlarından temin edilen günlük akım verileri dalgacık dönüşümüne tabi tutulmuş daha sonra da yapay sinir ağları yöntemi kullanılarak akışların yeni tahminleri yapılmıştır. Dalgacık dönüşümlü ve dönüşümsüz YAS modelleme sonuçları karşılaştırmalı olarak verilerek modellerin performansları tartışılmıştır.

\section{Materyal ve Metot}

\subsection{Yapay Sinir Ağları}

Yapay sinir ağları, insan beyninin çalışma mekanizması taklit edilerek geliştirilen ve beynin gerçekleştirdiği temel işlemlere belirli bir yaklaşımla ulaşmayı amaçlayan bir mantıksal programlama 
tekniğidir. İnsan beyninin taklit edilmesi çalışmalarında temel amaç, beynin paralel olarak çalışma, öğrenme, karar verme, esneklik ve yeni duruma adaptasyon özelliklerinin modellenmeye çalışılmasıdır. Yapay sinir ağları, yapılarına göre, İleri Beslemeli (Feedforward) ve Geri Beslemeli (Feedback) ağlar olmak üzere iki şekilde sınıflandırılırlar. İleri Beslemeli yapay sinir ağlarında nöronlar arasındaki iletişim giriş katmanından çıktı katmanına doğru tek yönlü bağlantılarla iletilir. Nöronlar bir katmandan diğer bir katmana bağlantı kurarlarken, aynı katman içerisindeki nöronlar birbiriyle bağlantılı değildir. $\mathrm{Bu}$ nedenle ileri beslemeli yapay sinir ağlarında, nöronlar arasındaki bağlantılar bir döngü oluşturmamakta ve bu ağlar girilen verilere hızlı bir şekilde çıktı üretebilmektedirler. Geri Beslemeli veya Yinelemeli (Recursive) yapay sinir ağları, ileri beslemeli ağların aksine dinamik bir yapıya sahiptir. Geri beslemeli yapay sinir ağlarında, çıktı veya ara katmanlardaki nöronlar çıktılarını giriş veya önceki ara katmanlardaki nöronlara tekrar girdi olarak iletirler. Böylece bilgi hem ileri hem de geri yönde aktarılmış olmaktadır. Geri beslemeli yapay sinir ağları dinamik hafızaya sahiptir ve bir andaki çıktı hem o andaki hem de önceki girdileri yansıtmaktadır [14].

$\mathrm{Bu}$ çalışmada Dicle nehrini besleyen Bitlis Deresine ait günlük akım serileri kullanılacaktır. DSİ akım gözlem istasyonlarından elde edilmiş ve Şekil 1'de verilen günlük akım serileri akım şeması Şekil 2'de verilen YSA sistemine girilerek modellenmiştir. Şekil 2'de gösterilen ağ açık döngü biçiminde oluşturulacak ve eğitilecektir. Kullanılan yapay sinir ağ yapısında 10 nöronlu 2 gecikmeli gizli katman (Hidden layer with delays) ve 1 çıktı katmanı (output layer) bulunmaktadır.
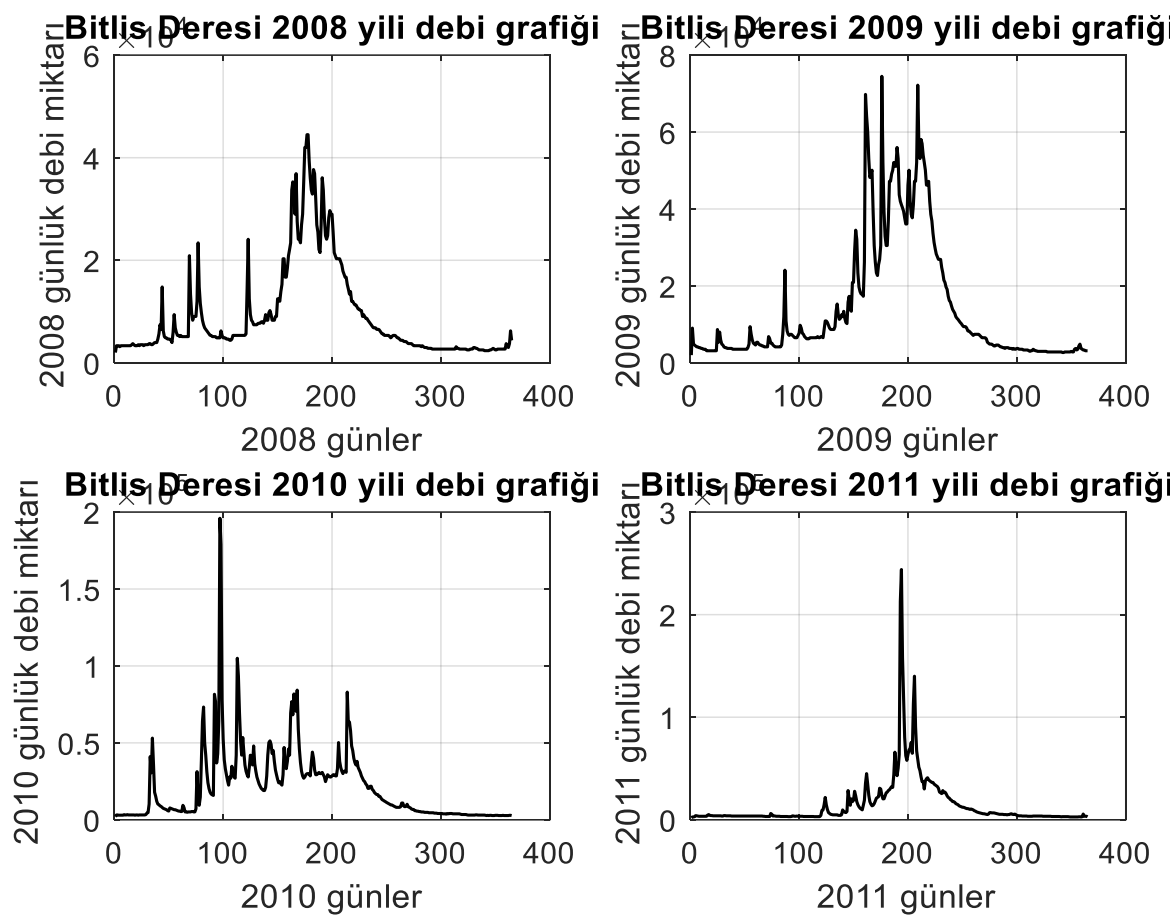

Şekil 1. Bitlis Deresine ait 2008-2011 debi verileri grafiği

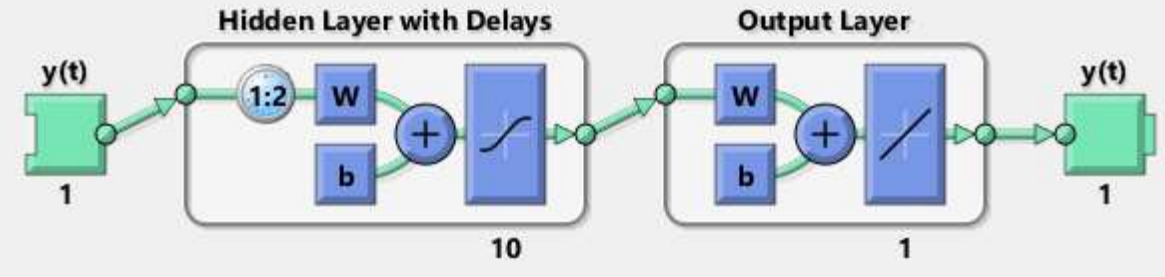

Şekil 2. Yapay sinir ağ yapısı

Problem tanımı olarak;

$y(t)=f(y(t-1), y(t-2), y(t-3), \ldots y(t-d))$ 
Buradaki, d=gecikme sayısıdır. Gizli katmana giren veriler $w, b$ gibi ağırlık katsayıları ve fonksiyon ile işlem yapılıp girdiler üzerinde çıktı değerleri üretmektedir. Buradaki asıl işlem ağırlıklar ayarlanarak hatayı en aza indirmektir. Ağırlık ayarlanıp hata en aza indirildiğinde ağın öğrenmesi tamamlanmış oluyor. YSA geri yayılım hesaplamasında, türevi kolay alınmasından ve sürekli olmasından dolayı, işlem kolaylığı sağlayan sigmoid transfer fonksiyonu kullanılmıştır [15]. Bunun dişında Tansig, Satlin, Purelin gibi transfer fonksiyonları da kullanılmaktadır. Yapay sinir ağ yapısı ekranın bu aşamasında kullanıcıya katmandaki nöron sayısını ve gecikme sayısını değiştirme imkânı vermekte ağın performansı düşük çıktığında bu değerler değiştirilerek en iyi performansı veren değerler denenmiştir.

\section{Bulgular ve Tartışma}

\subsection{YSA model sonuçları}

Farklı yılların akım serileri için yapay sinir ağına girilen nöron sayısı ve gecikme değerleri ile oluşan eğitimin ve testin regresyon değerleri Tablo 1'de verilmiş̧ir. Eğitim ve test regresyon oranlarının genel olarak \%90'ın üzerinde bir başarısı olduğu görülmektedir. Sadece 2010 yılına ait eğitim regresyon katsayıs1 en küçük değer olan \%88 olarak gerçekleşmiştir. Test oranında ise yine 2010 y1lı \%91 ile en düşük regresyon oranına sahiptir. 2010 yllındaki bu sapmanın nedeni Şekil 1'de görüldügü gibi 90. günlerde gerçekleşen aşırı büyük pik debi değeridir.

Tablo 1. Eğitim ve test sonuçlarının regresyon değerleri

\begin{tabular}{|c|c|c|c|c|}
\hline & & & Regresyon & Regresyon \\
\hline Y11 & Gizli katman nöron sayıs1 & Gecikme sayıs1 & Eğitim & Test \\
\hline 2008 & 10 & 2 & 0,974 & 0,962 \\
\hline 2009 & 10 & 2 & 0,974 & 0,988 \\
\hline 2010 & 10 & 2 & 0,876 & 0,912 \\
\hline 2011 & 10 & 2 & 0,937 & 0,968 \\
\hline
\end{tabular}

Eğitimi bittiğinde sonra YAS yardımıyla tahmin edilen ve gerçek akım değerleri karşılaştırmalı olarak Şekil 3'de verilmiştir. Şekil 4'de ise 2008-2011 yılları arası tüm günlük akım değerleri tek bir zaman serisi olarak analiz edilmiştir. 2010 ve 2011 yıllarındaki geçekleşen pik değerlerin diğer yıllara oranla oldukça büyük gerçekleştiği görülmektedir. Bu pik değerler mevsimsel değişim tahminlerini olumsuz etkilemektedir. Bu grafikler incelendiğinde pik debiler dışında kullanılan modelin çok iyi sonuçlar verdiği gözlemlenmiştir. Şekil 5 'te analiz edilen tüm yılların grafiksel başarı istatistikleri ayrıntılı olarak verilmiştir. Bu istatistiklere göre modelin en başarılı olduğu y1l 2008 yılı verileridir. $\mathrm{Bu}$ yılda eğitim, geçerlilik ve test istatistiklerinin de en iyi olduğu görülmektedir. En düşük değerler ise aşırı pik debilerden dolay1, \%90 ve \%93 regresyon ile yine 2010 ve 2011 yılarında gözlenmiştir. Tüm yıllar için ortalama regresyon \%94.6 gibi bir regresyon elde edilmiştir.

Genel olarak modelin pik debilerde genel trende daha yakın olduğundan daha küçük değerler verdiği gözlemlenmiştir. İstatiksel açıdan bakıldığında bunun beklenen bir sonuç olduğu söylenebilir. Ancak hidrolojik süreçler bakımından pik debilerin özellikle taşkın kontrolü açısından anlamları büyüktür. Bu nedenle bu sonuçlar akımların doğru tahminleri açısından ve genel olarak su yapılarının tasarımı açısından oldukça iyi sonuçlar verse de pik debilerin tahmininde (ki beklenen en yüksek değerlerin tahmini için hidrolojide dağılım fonksiyonları gibi başka yöntemler kullanılır) kullanılması uygun olmayacaktır. İstatiksel eğilimlerde genel olarak bu uç değerler sapma değerleri olarak görülür ve gerçekleşme olasılığı çok belirsiz ve az olduğundan bu değerler görmezden gelinebilir veya yumuşatılır. Fakat bu pik değerlerin hiç dikkate alınmaması hidrolojik süreçler bakımından uygun olmayacaktır. Bu nedenle daha kuramsal bir yaklaşım olarak bu değerlerin gerçekleşmesi mümkün fakat genel eğilime daha yatkın kılabilmek için ek yöntemler uygulanacaktır. Bu amaçla aynı akım serileri üzerine dalgacık dönüşümlü (Wavelet) bir YAS modeli uygulanmıştır. 

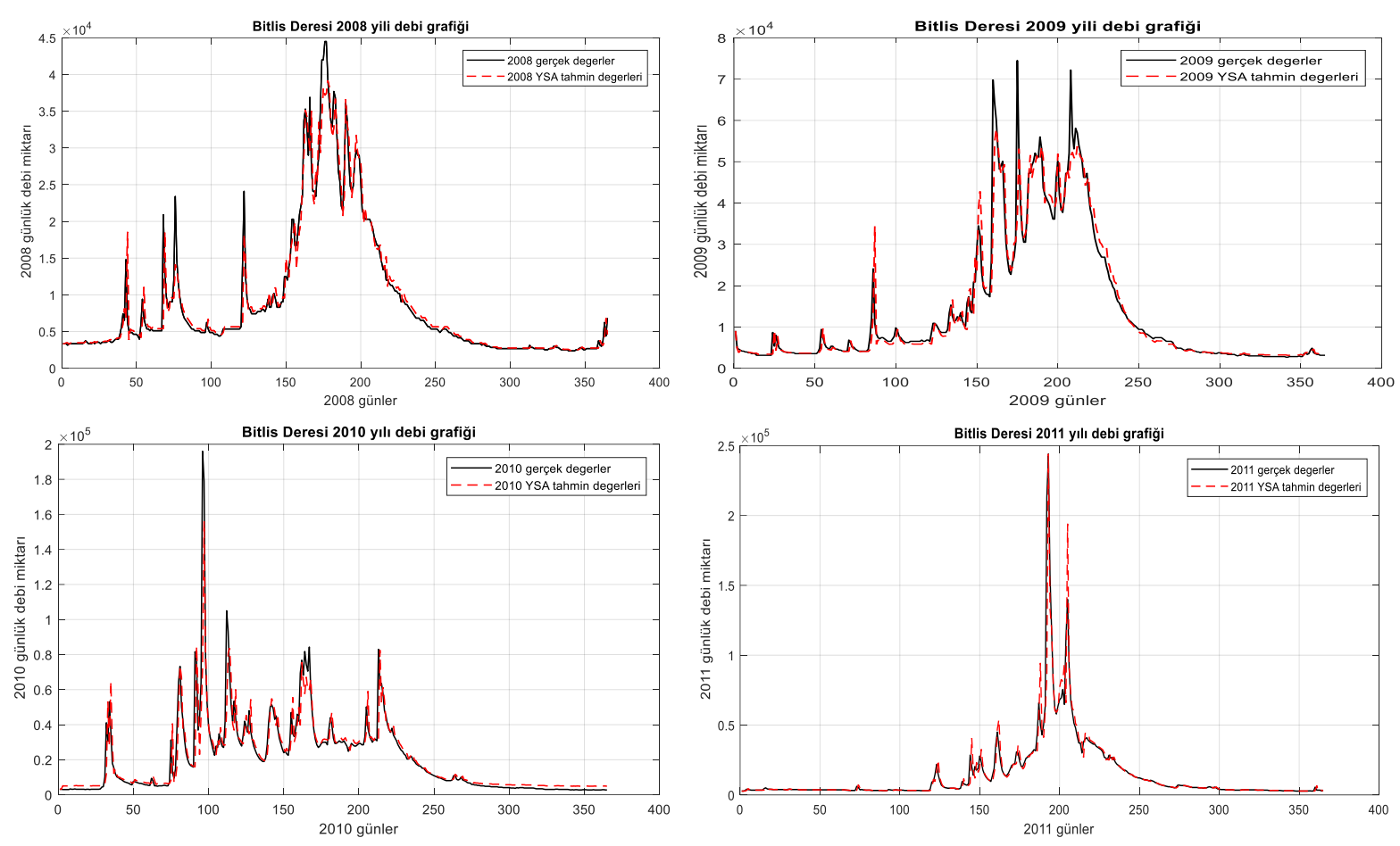

Şekil 3. Yıllara göre günlük akım değerlerinin YSA model tahminleriyle karşıllaştırılması

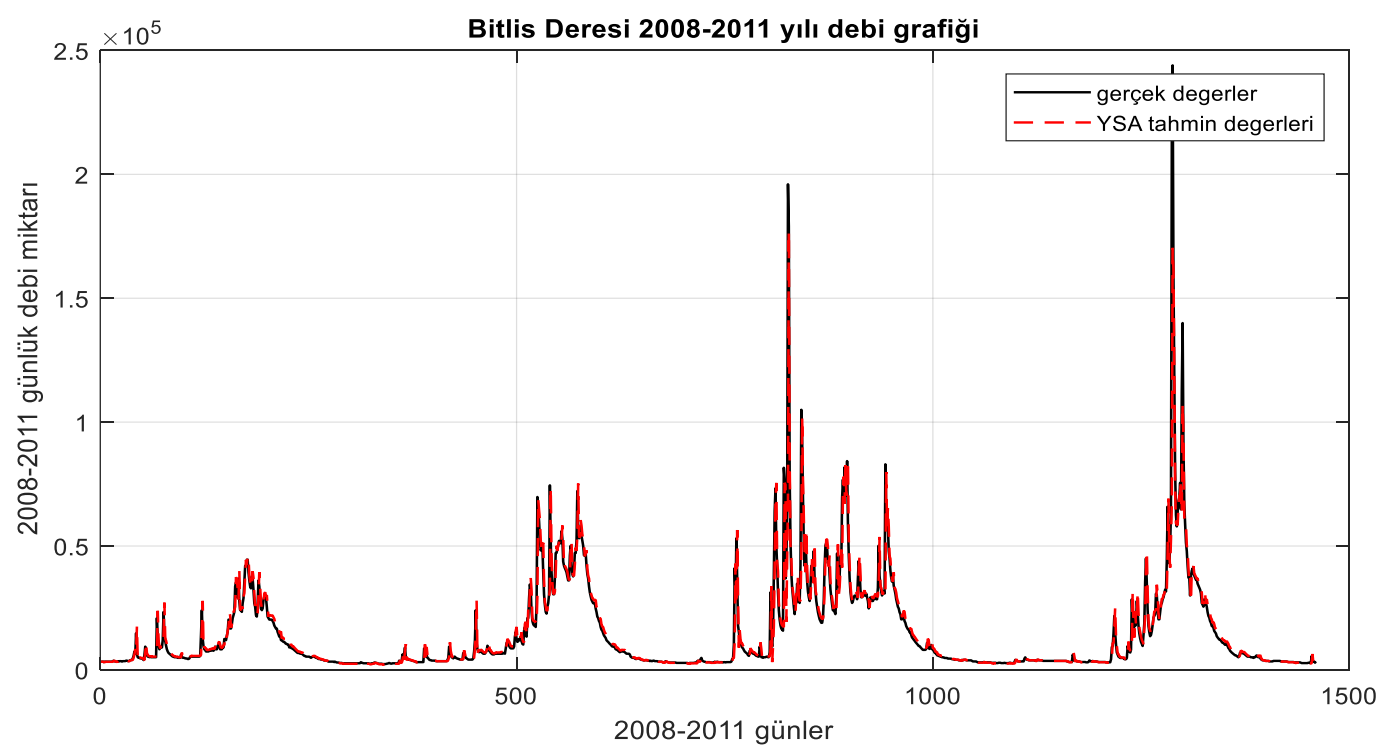

Şekil 4. 2008-2011 yılları arası gerçek değerler ve tahmin değerleri karşılaştırma grafiği 

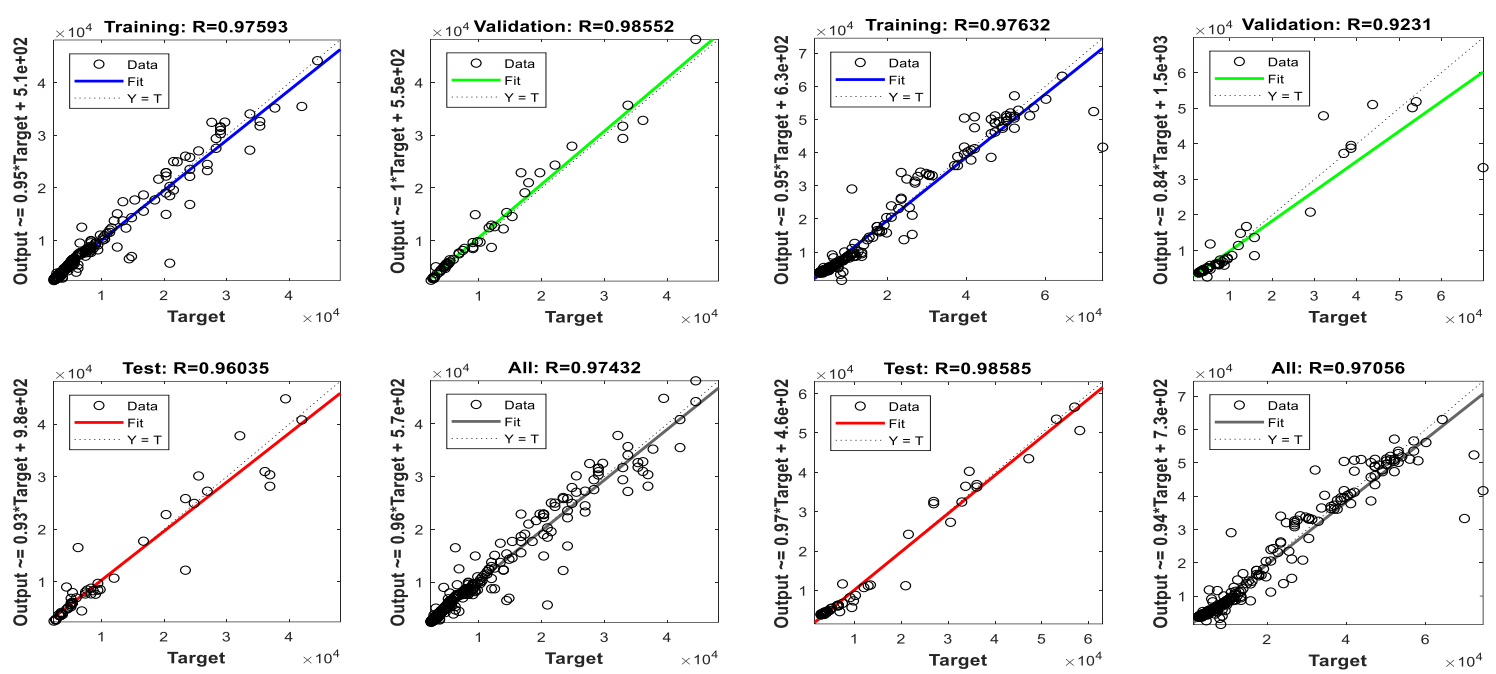

a) 2008

b) 2009
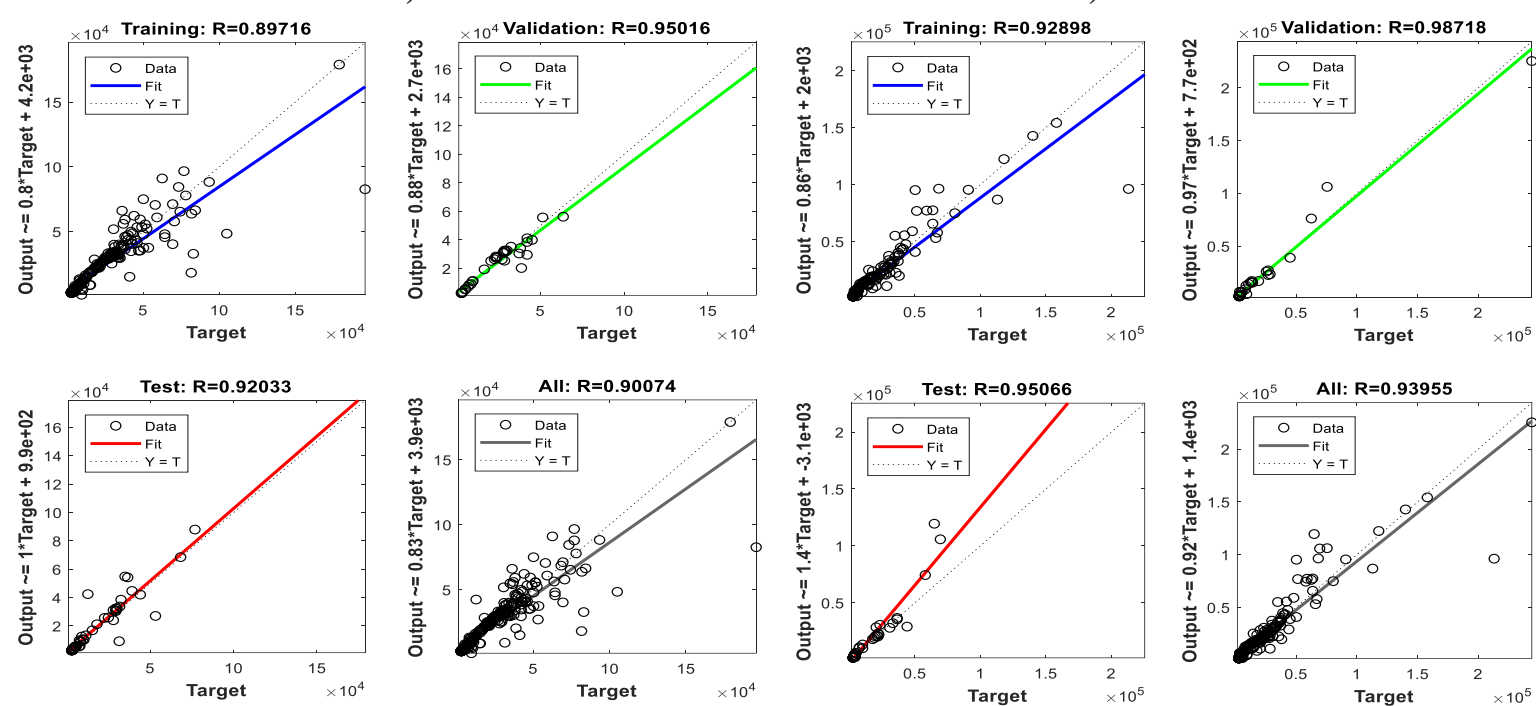

c) 2010
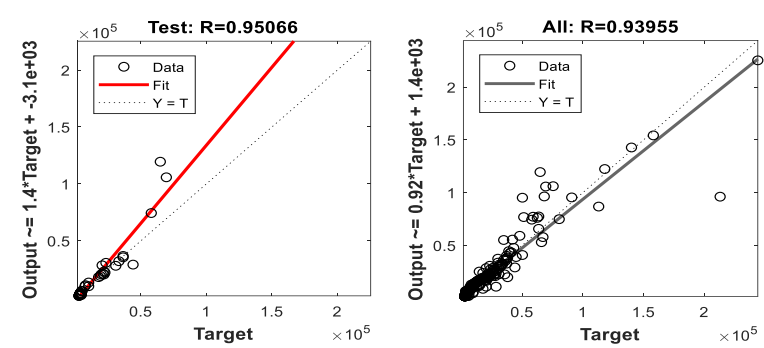

Şekil 5. Her bir yıl için YAS modelinin başarı istatistikleri

\subsection{Dalgacık Dönüşümlü YAS Model}

Bölgenin iklimi ve coğrafyası gibi birçok değişken verileri etkilemekte olduğundan hidrolojik zaman serisine bakarak sonuçları değerlendirmek oldukça zordur. Bununla birlikte bu etkilenme uzun zaman diliminde baktığımızda kendini tekrarlayan periyodik fonksiyonlara dönüşmekte dolayısıyla zaman serilerinde frekans dizilimine dönüştürülüp değerlendirmek daha olumlu sonuçlar vereceği bilinmektedir. Frekans dizilimindeki sinyallerin analizi, hidrolojik süreçler gibi doğa olaylarının davranışı hakkında daha detaylı bilgi verebilir. Dalgacık dönüşümü (wavelet transform) son yıllarda verilerin analizinde sıkça kullanılmaya başlayan bir sinyal işleme tekniğidir. Dalgacık dönüşümü, veri sinyali ile ana dalgacık denilen sinyallerin bileşimi olarak ortaya çıkar. Bu dönüşümde girilen veriler yani bir ana dalgacık ile birleştirilir ve elde edilen sinyal ölçeklendirilerek zaman boyutunda değerlendirilir. Dolayısıyla zaman ölçeğinde elde edilen bu seriler frekans bilgisini de içerir. Elde edilen sinyaller hem frekans hem de zaman bölgesinde incelenebildiğinden dalgacık dönüşümleri Fourier dönüşümlerine göre daha fazla avantaj sağlar. Belli zaman periyotları içeren hidrolojik süreçlerin bu dönüşüme tabi tutulması verilerin analizini kolaylaştıracağı düşüncesiyle çalışmanın bu bölümünde gözlem değerleri dalgacık (wavelet) dönüşümüne tabi tutulmuştur. $\mathrm{Bu}$ amaçla wavelet ailesinden Daubechies'in $d b$ 6. üyesiyle analizi yapılmış olup Dalgacık-YSA (Wavelet-ANN) hibrid model sonucu elde edilmiş olan tahmin değerleri elde edilmiştir. Bu tahmin değerleriyle gerçek akım değerleri karşılaştırmalı olarak Şekil 6'daki grafiklerle verilmiştir. Grafiklerde görüleceği gibi dalgacık dönüşümlü YSA modelinin pik debiler dâhil daha iyi bir benzeşim sağladığı görülmektedir. Bu modelin 
yıllara göre başarı istatistikleri ise Şekil 6'da verilmektedir. Görüleceği gibi daha önce en düşük gözlemlenen 2010 ve 2011 yıllarındaki regresyon katsayısının \%96'ya çıtığı görülmektedir. Tüm yılların başarı ortalaması ise \%94.6'dan \%97.7'ye yükselmiştir. Pik debilerdeki daha iyi benzeşim ve genel regresyon ortalamasındaki yükselme Dalgacık Dönüşümlü YSA modelin günlük akım serilerinin benzeşiminde oldukça başarılı olduğunu göstermektedir.

Tablo 2. Dalgacık dönüşümlü ve dönüşümsüz YSA model regresyon oranlarının karşılaştırılması

\begin{tabular}{|c|c|c|}
\hline Y11 & YSA (ANN) & Dalgac1k-YSA (Wavelet-ANN) \\
\hline 2008 & 0.974 & 0.993 \\
\hline 2009 & 0.971 & 0.988 \\
\hline 2010 & 0.900 & 0.962 \\
\hline 2011 & 0.940 & 0.964 \\
\hline
\end{tabular}
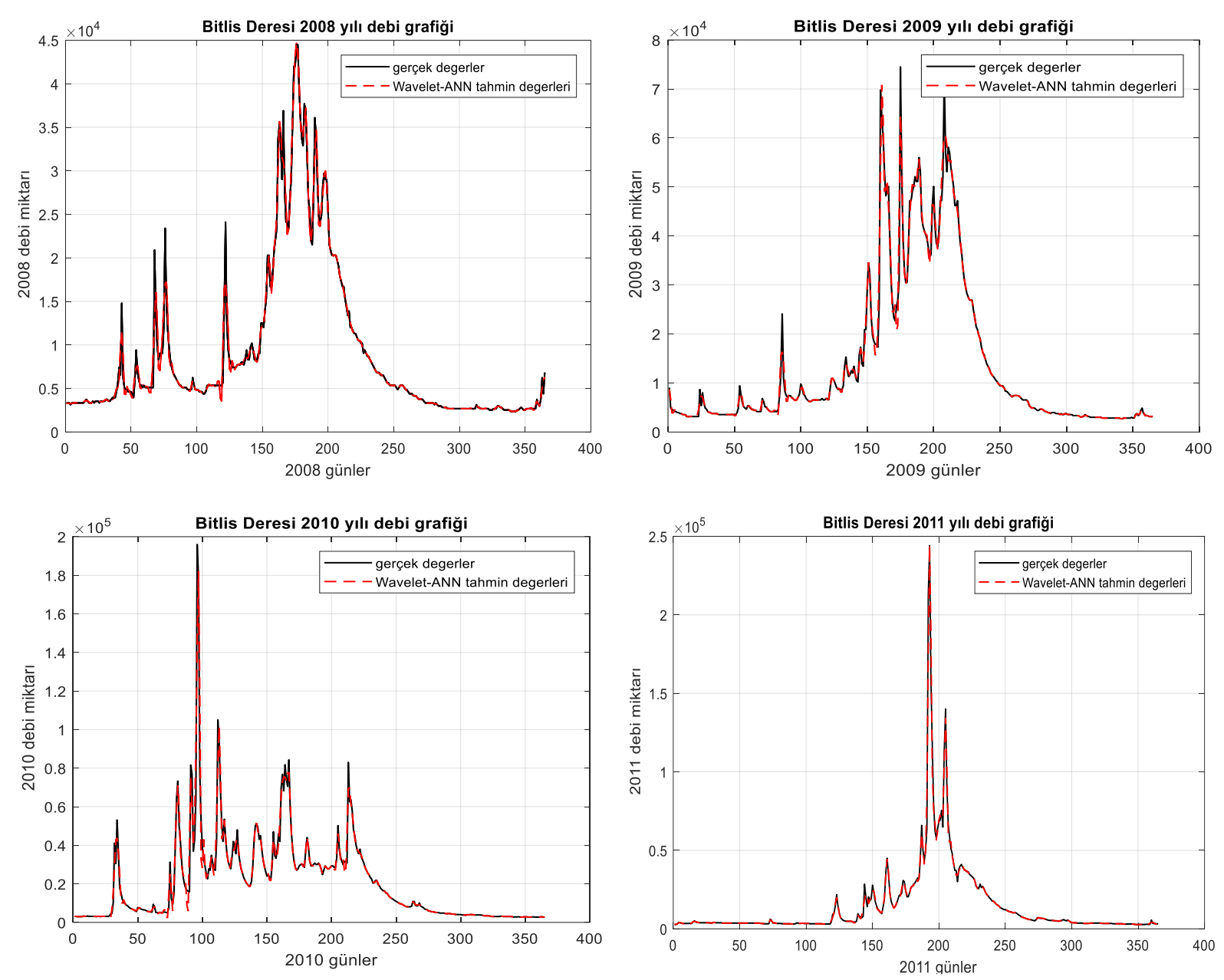

Şekil 6. Dalgacık (wavelet)-YSA modeli tahmin değerlerinin gerçek akım serileriyle karşılaştırması 

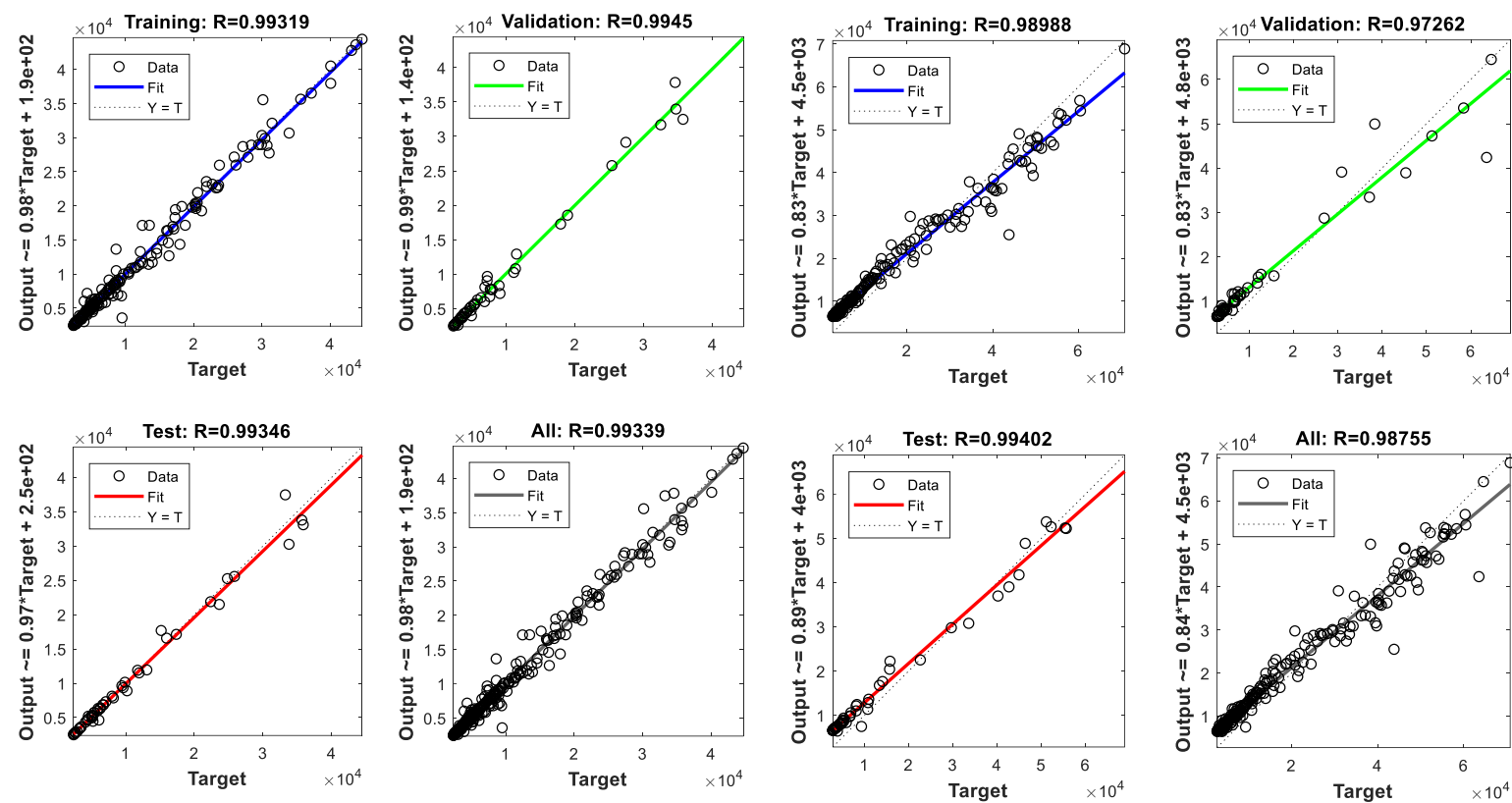

a) 2008
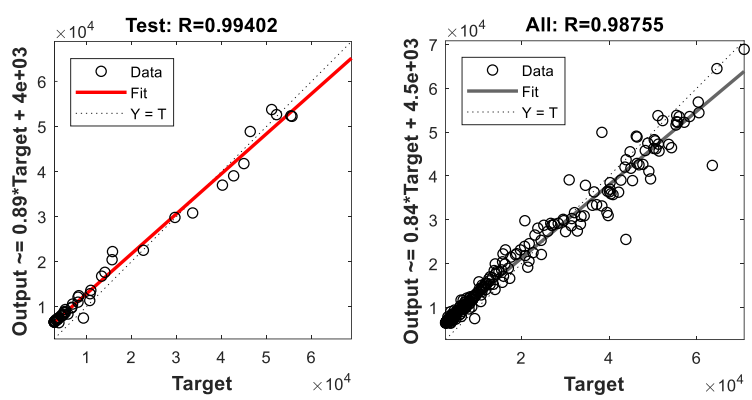

b) 2009
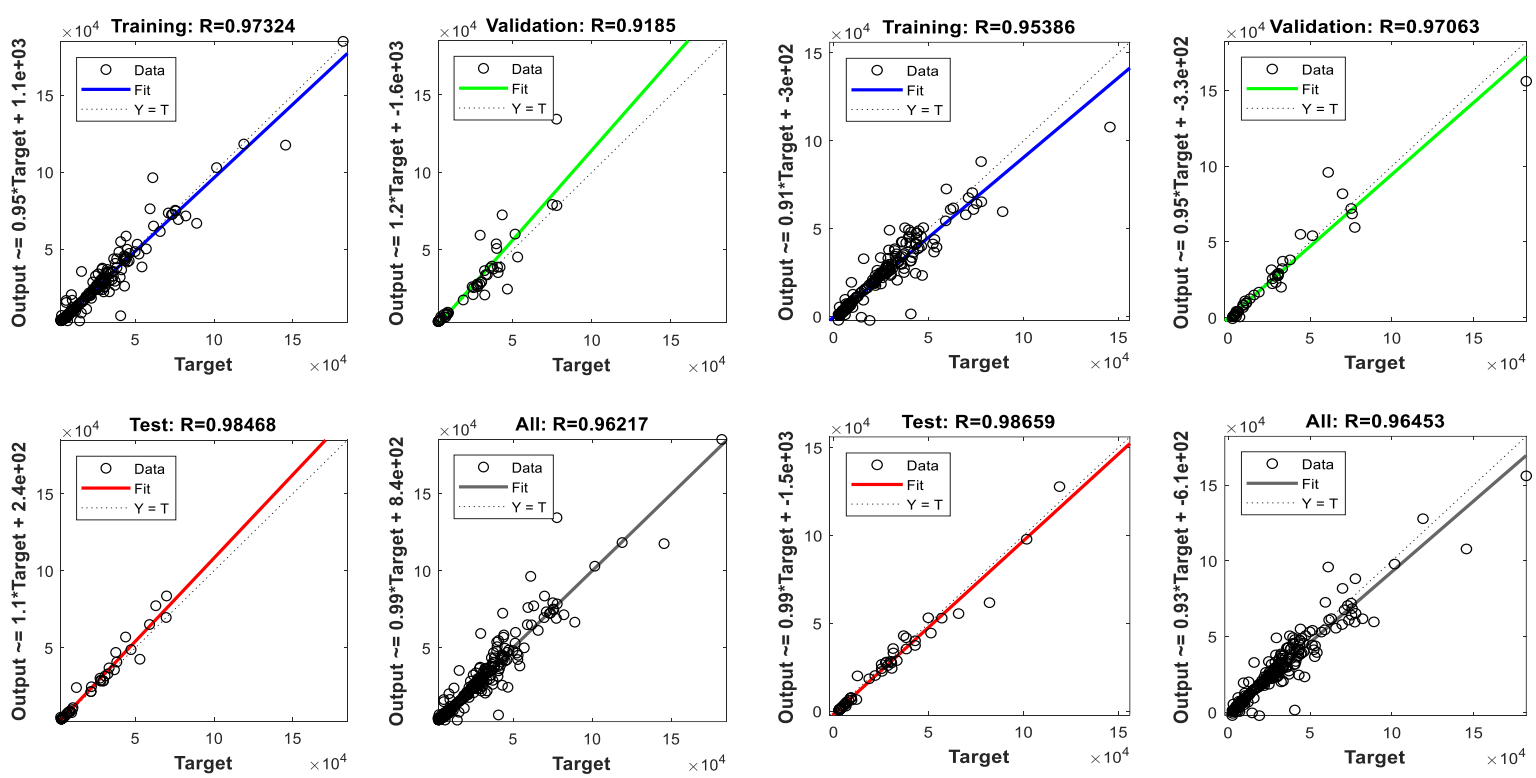

c) 2010
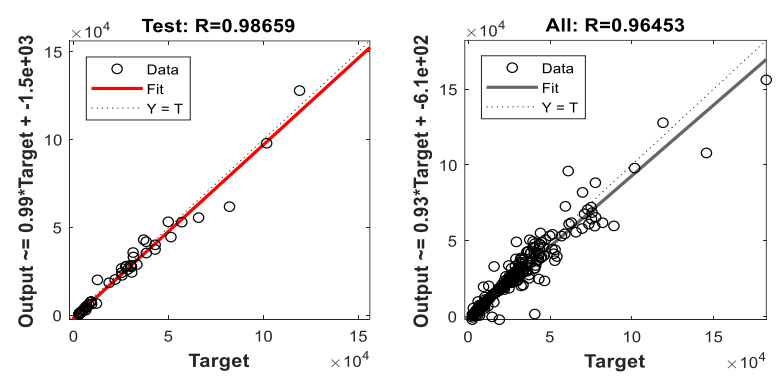

d) 2011

Şekil 7. Dalgacık Dönüşümlü YSA modelinin Başarı istatistikleri

\section{Sonuç}

Taşkın koruma, nehir santralleri, su yapıları gibi projelerde akarsuların uzun yıllara ait akım verileri gerekmektedir. Akım verilerin maksimum ve minimum debileri, eksik verilerin tamamlanması gibi hidrolojik verilerin analizi önem arz etmektedir. Bu çalışmada, standart bir YSA ve dalgacik dönüşümlü YSA modelleri kullanılarak bir akarsuya ait günlü akım serileri modellenmiştir. Elde edilen tahmin değerleri gerçek akım değerleriyle karşılaştırılmıştır. Her iki model genel manada iyi sonuç vermekle birlikte özellikle aşırı pik debilerinin oluştuğu yıllarda standart dalgacık dönüşümlü YSA model standart YSA modelden çok daha iyi sonuçlar verdiği gözlemlenmiştir. Standart YSA model, aşırı uç değerleri yumuşatarak genel gidişata uygun sonuçlar vermektedir. Uç değerlerin yumuşatılması hatta ihmal edilmesi istatistiksel olarak uygun görülse de özellikle taşkın kontrolü gibi uygulamalarda bu uç değerlerin doğru tahmini hidrolojik açıdan oldukça önemlidir. Bu nedenle günlük akım serileri gibi hidrolojik süreçlerin tahmininde dalgacık dönüşümlü YSA modellerin oldukça başarılı sonuçlar verdiği söylenebilir. Bu modeller hidrolojide önemli bir yer tutan ileriye dönük akım tahminlerinde ve eksik 
verilerin tamamlanmasında kullanılabileceği gibi hazne işletme ve havza modelleme gibi su kaynakların plan ve projelendirme çalışmalarında da kullanılabilir.

\section{Yazarların Katkısı}

Çalışmada tüm yazarlar eşit oranda katkı sunmuştur

\section{Çıkar Çatışması Beyanı}

Yazarlar arasında herhangi bir çıkar çatışması bulunmamaktadır.

\section{Araştırma ve Yayın Etiği Beyanı}

Yapılan çalışmada araştırma ve yayın etiğine uyulmuştur.

\section{Kaynaklar}

[1] Çuhadar M., Kayacan C. 2005. Yapay Sinir Ağları Kullanılarak Konaklama İşletmelerinde Doluluk Oranı Tahmini: Türkiye'deki Konaklama İşletmeleri Üzerine Bir Deneme. Anatolia: Turizm Araştırmaları Dergisi, 16 (1).

[2] Kızılaslan M.A., Sağın F., Doğan E., Sönmez O. 2014. Aşağı Sakarya Nehri akımlarının yapay sinir ağları ile tahmin edilmesi. Sakarya University Journal of Science, 18 (2): 99-103.

[3] Okkan U., Mollamahmutoğlu A. 2010. Yiğitler Çayı Günlük Akımlarının Yapay Sinir Ağları ve Regresyon Analizi ile Modellenmesi. Dumlupınar Üniversitesi Fen Bilimleri Enstitüsü Dergisi, 23: 33-48.

[4] Gemici E., Ardıçlığlu M., Kocabaş F. 2013. Akarsularda debinin yapay zeka yöntemleri ile modellenmesi. Erciyes Üniversitesi Fen Bilimleri Enstitüsü Fen Bilimleri Dergisi, 29 (2): 135 143.

[5] Hsu K.I., Gupta H.V., Sorooshian S. 1995. Artificial neural network modeling of the rainfallrunoff process. Water Resour. Res., 31: 2517-2530.

[6] Nourani V., Kisi Ö., Komasi M. 2011. Two hybrid Artificial Intelligence approaches for modeling rainfall-runoff process. J. Hydrol., 402: 41-59.

[7] Adamowski J., Chan H.F. 2011. A wavelet neural network conjunction model for groundwater level forecasting. J. Hydrol., 407: 28-40.

[8] Pramanik N., Panda R., Singh A. 2011. Daily river flow forecasting using wavelet ANN hybrid models. J. Hydroinformatics, 13: 49-63.

[9] Alizadeh M.J., Kavianpour M.R. 2015. Development of wavelet-ANN models to predict water quality parameters in Hilo Bay, Pacific Ocean. Mar. Pollut. Bull., 98: 171-178.

[10] Alizadeh M.J., Kavianpour M.R., Kisi O., Nourani V. 2017. A new approach for simulating and forecasting the rainfall-runoff process within the next two months. Journal of Hydrology, 548: 588-597.

[11] Aydın M.C., Cömert Z., Işı1k E., Büyüksaraç A., Ulu A.E. 2018. Estimation of Flow Series using Discrete Wavelet Analysis and Artificial Neural Networks. 4th International Conference on Engineering and Natural Science, 2-6 May 2018, Kiev, Ukranie.

[12] Nourani V., Tahershamsi A., Abbaszadeh P., Shahrabi, J., Hadavandi E. 2014. A new hybrid algorithm for rainfall-runoff process modeling based on the wavelet transform and genetic fuzzy system. Journal of Hydroinformatics, 16: 1004-1024.

[13] Nourani V., Alami M.T., Aminfar M.H. 2009. A combined neural-wavelet model for prediction of Ligvanchai watershed precipitation. Engineering Applications of Artificial Intelligence, 22: 466-472.

[14] Bayır F. 2006. Yapay Sinir Ağları ve Tahmin Modellemesi Üzerine Bir Uygulama. Yüksek Lisans Tezi, İstanbul Üniversitesi, Fen Bilimleri Enstitüsü, İstanbul.

[15] İlkuçar M., Kaya A.İ., Çifci A. 2018. Mekanik Özelliklere Göre Ağaç Türlerinin Yapay Sinir Ağları ile Tahmini. Gümüşhane Üniversitesi Fen Bilimleri Enstitüsü Dergisi, 8 (1): 75-83. 